\title{
150th Anniversary AGM Attendees
}

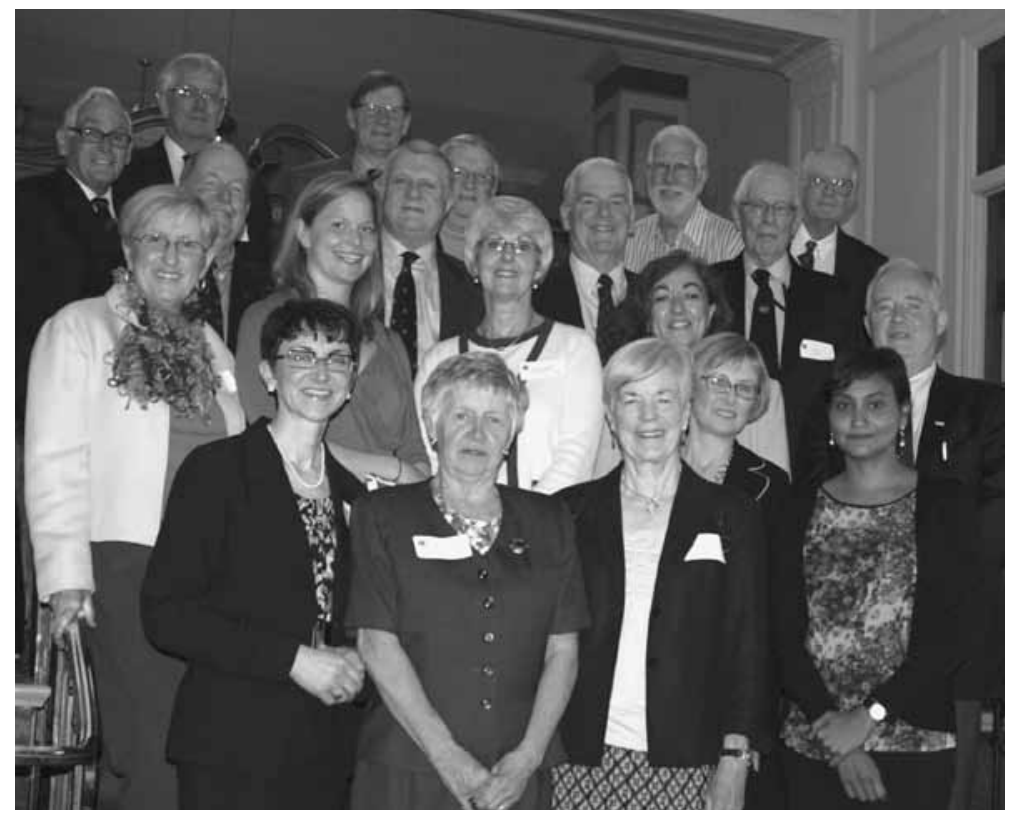

Front row (l-r): Michelle Paon, Elaine McCulloch, Anne Mills, Linda Marks, Suzuette Soomai.

2nd row: Heather Cook, Leigh-Ann Bishop, Sharon Longard, Angelica Silva, Peter Wells.

3rd row: Bob Cook, John Young, Henry (Hank) Bird, Eric Mills.

Back row: Truman Layton, John Rutherford, David Richardson, Archie McCulloch, Alan Ruffman, Stuart Grossert. 
